\title{
Study of the Inhibitive Action of Bakery Waste for Corrosion of Mild Steel in Acid Medium
}

\author{
R. Rajalakshmi", S. Subhashini, S. Leelavathi and R. Geethanjali \\ Department of Chemistry, Avinashilingam Univ. for Women, Coimbatore-641043, India. \\ e-mail: raji_adu@yahoo.com, leelasubu@gmail.com
}

\begin{abstract}
Bakery waste-egg shell extract was tested for its inhibitory effect towards mild steel in $0.5 \mathrm{M} \mathrm{H}_{2} \mathrm{SO}_{4}$ solution. The corrosion behavior of the egg shell extract on mild steel (MS) was investigated using weight loss experiments, polarization and impedance measurements. It was found that the egg shell extract has good inhibitive action, showing $97.8 \%$ efficiency. Inhibition efficiency increased with increasing concentrations of the egg shell extract. Temperature studies were conducted to evaluate the kinetic and thermodynamic parameters. The corrosion inhibition takes place via monolayer type of adsorption on MS surface. Experimental results are fitted into various adsorption isotherms. Tafel polarization studies revealed the mixed mode of inhibition of the egg shell extract. Electrochemical impedance results also confirmed the inhibitive nature of the egg shell extract. The results obtained showed that the extract of the egg shell could serve as an effective, zero cost, environmentally friendly inhibitor for the corrosion of mild steel in sulphuric acid medium.
\end{abstract}

Keywords: Egg shell, corrosion, inhibition, mild steel, $\mathrm{H}_{2} \mathrm{SO}_{4}$ solution.

\section{Introduction}

Mild steel is a structural material of choice to fabricate various reaction vessels, pipes, tanks and so on in sugar, petrochemical, brewery, food, paper, textile and marine industries. Mild steel suffers from severe corrosion in aggressive environment, which needs to be protected. The pickling, descaling and chemical cleaning are processes in which metals are subjected to aggressive acids like $\mathrm{HCl}$ and $\mathrm{H}_{2} \mathrm{SO}_{4}$. In such cases, conditions must be created so as to minimize the dissolution of the base metals after scale removal. Ashassi-Sorkhabi ${ }^{1}$ studied the inhibition effect of amino acids (alanine, glycine, leucine) against steel corrosion in $\mathrm{HCl}$ solution. Keny et al. ${ }^{2}$ explained that gallic acid acted as an effective corrosion inhibitor. According to Loto et al. ${ }^{3}$ cashew juice extract was used as a corrosion

${ }^{*}$ Corresponding author 
inhibitor for mild steel in acid medium. This can be achieved solely with the use of corrosion inhibitors, which are mostly organic compounds.

Corrosion inhibition is a surface process with specific adsorption of inhibitor on the metal surface. In recent years, attempts have been made to understand the nature of interaction between the inhibitor and metal surface in terms of adsorption isotherm. The knowledge of the adsorption behavior of the inhibitor is important for the definition of its active mechanism. For this reason, the dependence of surface coverage on concentration is studied through these two adsorption isotherms; Langmuir $[(\log \theta / 1-\theta)$ vs $\log C]$ and Temkin $(\theta$ vs $\log C)$.

According to Shreir ${ }^{4}$, the cost is one of the relevant points if an inhibitor to control corrosion in a process is to be adopted. A.Y. El-Etre et al. ${ }^{5}$ proved that the aqueous extract of the leaves of henna (lawsonia) acted as a good corrosion inhibitor. The degree of inhibition depends on the nature of metal and type of medium. The inhibitive action is mostly due to the products of the hydrolysis of the protein content of the plants ${ }^{6}$. Researchers have been carried out on the inhibiting properties of some naturally occurring substances $^{7-16}$ and industrial byproducts ${ }^{17,}{ }^{18}$ which can be easily obtained from cheap resources. Corrosion inhibition was studied with the extracts of Thespesia populnea ${ }^{19}$, Sesbania grandiflora seeds ${ }^{20}$, Ficus benghalensis bark $^{21}$, Psidium gujava (bark) and Callistemon (leaves) ${ }^{22}$, Canavalia ensiformis ${ }^{23}$, Phaseolus aureus seeds ${ }^{24}$ etc. The natural inhibitors studied have been found to be highly eco-friendly and possess no threat to the environment.

The inhibitive nature of amino acids was studied by Abdullah and Vita ${ }^{26}$. The mixture of amino acids is a promising inhibitor for mild steel corrosion. The lone pair of electrons available on the $\mathrm{N}, \mathrm{O}$ and Sulphur atoms present in the amino acid might have readily formed co-ordinate bond with the empty $d$ orbital of iron. Thus, they form a thin film on the metal surface preventing the dissolution of the metal. The adsorption of the constituents is further confirmed by the adsorption isotherm, negative free energy and exothermic nature of adsorption. Due to the presence of mixture of amino acids the inhibition was more effective. In acidic medium, some of the amino acids are present as cations and some as anions depending on their iso-electric point. The cations and anions get adsorbed on the cathodic and anodic sites respectively on the metal surface. This type of inhibition process will help in the enhancement of protecting ability of the extract understudy.

Furthermore, the egg shells mostly contain calcium carbonate. On heat processing with acid, calcium carbonate becomes insoluble calcium oxide. Thus, the extract is rich in various amino acids constituents like alanine, arginine, ash, aspartic acid, $\mathrm{CaCO} 3$, calcium, crude fat, cystine, glutamic acid, glycine, histidine, isoleucine, leucine, lysine, magnesium, methionine, phenylalanine, phosphorus, potassium, proline, protein, serine, sulphur, threonine, tyrosine, valine and water adapted from animal by-product processing and utilization $^{25}$. Therefore, in the present investigation, efforts are taken to study the inhibitive action of the extract of egg shell as an ecofriendly "zero cost" corrosion inhibitor for mild steel in $0.5 \mathrm{M}$ sulphuric acid. 


\section{Experimental Methods}

MS specimen of chemical composition C-0.081, Mn-0.296, Si-0.016, P-0.032, S0.014 , Cr-0.021, Mo-0.019, Ni-0.016 and remaining iron was cut into pieces of area $5 \times 1$ $\mathrm{cm}^{2}$. The specimens were polished mechanically, degreased, cleaned successively in deionized water, dried, stored in a dessicator and used for all studies. The experiment was carried out in $0.5 \mathrm{M}$ sulphuric acid.

The egg shells were collected from a nearby bakery shop and air dried. About $25 \mathrm{~g}$ of the shells were weighed and refluxed in $500 \mathrm{ml}$ of $0.5 \mathrm{M}$ sulphuric acid for $3 \mathrm{~h}$. It was kept overnight and filtered to get $5 \%$ extract.

The weight loss method was used to monitor the corrosion rate. In this present work, pre-weighed coupons were immersed in triplicate with the help of glass hook into a beaker containing $100 \mathrm{ml}$ of acid with and without inhibitor for a particular period of time. The coupons are then washed, dried and reweighed. The average weight loss of the coupons was recorded. The experiments were carried out varying different parameters like concentration (0.05-0.5 \%), time of immersion $(1 / 2,3,6$, 12 and $24 \mathrm{~h})$ and temperature $\left(303-353^{\circ} \mathrm{K}\right)$. The percentage of inhibition efficiency and surface coverage were calculated using equations (1) and (2), respectively.

$$
\begin{aligned}
\text { Inhibition efficiency }(\%) & =\left(\left(\mathrm{W}_{0}-\mathrm{W}\right) / \mathrm{W}_{0}\right) \times 100 \\
\text { Surface coverage }(\theta) & =\left(\mathrm{W}_{0}-\mathrm{W}\right) / \mathrm{W}_{0}
\end{aligned}
$$

where, $\mathrm{W}_{0}$ is corrosion rate without inhibitor in $\mathrm{g}, \mathrm{W}$ is corrosion rate in inhibitor in $\mathrm{g}$.

The change in free energy $(\Delta \mathrm{G})$ of adsorption of the inhibitors can be calculated by using equation (3) ${ }^{27}$.

$$
\log \mathrm{C}=[\log \theta /(1-\theta)]-\log \mathrm{B}
$$

where, $\log \mathrm{B}=-1.74-(\Delta \mathrm{G} / 2.303 \mathrm{RT}), \theta$ is the surface coverage, $\mathrm{C}$ is the concentration the inhibitor, $\mathrm{R}$ is the gas constant $(8.314 \mathrm{~J} / \mathrm{mol})$ and $\mathrm{T}$ is the temperature in $\mathrm{K}$.

The values of enthalpy of adsorption $\Delta \mathrm{H}$ and entropy of adsorption $\Delta \mathrm{S}$ were obtained from the basic thermodynamic equation, that is, Gibbs Helmholtz equation, $\Delta \mathrm{G}=\Delta \mathrm{H}-\mathrm{T} \Delta \mathrm{S}$. A plot of $\Delta \mathrm{G}$ versus $\mathrm{T}$ gives a straight line with intercept $\Delta \mathrm{H}$ and slope $\Delta \mathrm{S}$.

The activation energy at different concentration of the inhibitor at various temperatures was determined by plotting $\log \mathrm{CR}$ vs $1 / \mathrm{T}$ (Arrhenius plot) and from the slope of the plot, activation energy $\left(E_{a}\right)$ was calculated using the formula of $E_{a}=$ $-2.303 \times \mathrm{R} \times$ slope of the Arrhenius plot.

The most commonly used techniques like potentiodynamic polarization method, linear polarization resistance method and electrochemical impedance spectroscopy (EIS) method have been used to measure the corrosion rate in the present investigation. Solartron electrochemical measurement unit - 1280B model was used with software package of 
Corrware and $\mathrm{Z}$ plot. The system includes a potentiostat, personal computer and frequency response analyzer. The electrochemical measurements were performed in a typical threeelectrode system consisting of the MS specimen as working electrode (WE), platinum electrode as counter electrode (CE) and a saturated calomel electrode (SCE) as the reference electrode. The electrode potential was allowed to stabilize for $1 \mathrm{~h}$ before starting the measurements. All the experiments were carried out at room temperature. For potentiodynamic polarization studies, mild steel specimens coated with lacquer with an exposed area of $1 \mathrm{~cm}^{2}$ was used.

Impedance measurements were carried out at corrosion potential $\left(\mathrm{E}_{\mathrm{corr}}\right)$. The A.C. amplitude of $10 \mathrm{mV}$ was applied and the frequency was varied from $10 \mathrm{kHz}$ to $10 \mathrm{mHz}$. The real and imaginary parts of the impedance were plotted in Nyquist plot. From the Nyquist plots and Bode plots, the charge transfer resistance $\left(\mathrm{R}_{\mathrm{ct}}\right)$ and double layer capacitance $\left(\mathrm{C}_{\mathrm{dl}}\right)$ values were calculated. Values of corrosion current were obtained by Tafel extrapolation method. In Tafel extrapolation method, plots of $\eta$ vs $\log$ current were made and an extrapolation of linear portion to the corrosion potential gave the corrosion current and the slope of the linear portion of the anodic and cathodic curves gave $b_{a}$ and $b_{c}$, respectively. $R_{p}$ was obtained from the linear polarization resistance curves.

\section{Results and Discussion}

The inhibition efficiency of the extract depends on the concentration of the extract, time of immersion and temperature. Results indicated a significant decrease in the corrosion rate with 0.1 to $0.5 \%$ extract of egg shell. The maximum inhibition efficiency is $97.8 \%$ with $0.5 \%$ concentration of the extract. At all test durations $0.5 \%$ extract showed maximum efficiency (Figure 1). It may be due to the increase in the surface coverage of MS with the inhibitor. As the time of immersion increases from $1 / 2$ to $12 \mathrm{~h}$, the IE also increases from 83 to $97 \%$ at $0.5 \%$ concentration. There is a slight decrease in IE after $12 \mathrm{~h}$. This may be explained due to increase of adsorbed of inhibitor molecules on MS surface with time. Prolonged immersion may result in desorption of the extract from MS surface.

As the concentration of the extract increases, the IE increases for all the temperatures (Figure 2). To determine the energy of activation and thermodynamic parameters, weight loss measurements were carried out from $303-353 \mathrm{~K}$ in the absence and presence of various concentrations of the egg shell extract. As the temperature increased from 303 to $323 \mathrm{~K}$, the IE also increased from 83 to $88 \%$ at $0.5 \%$ concentration. After $323 \mathrm{~K}$, IE decreased with increasing temperature. This may be explained as adsorption and desorption of inhibitor molecules continuously occur at the metal surface and equilibrium exists between these two processes at a particular temperature. With the increase in temperature, the equilibrium between adsorption and desorption process is shifted leading to a higher desorption rate than adsorption until equilibrium is again established at a different value of equilibrium constant. This explains the lower IE at higher temperature. 


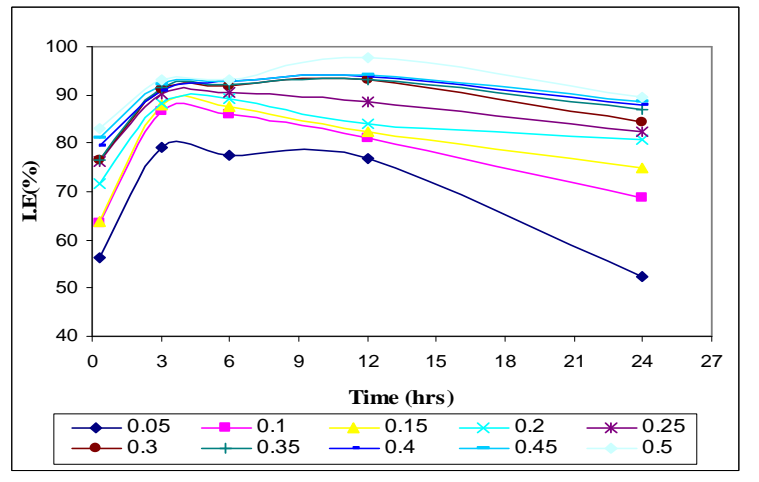

Figure 1: Changes of inhibitor efficiency as a function of concentration of the egg shell extract at various periods of immersion.

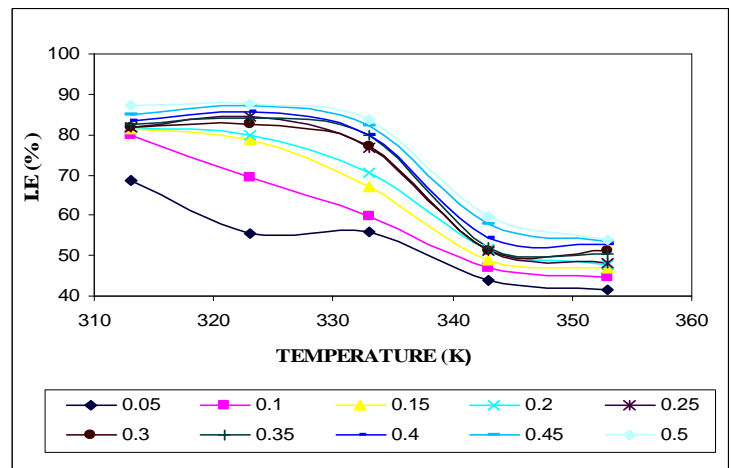

Figure 2: Changes of inhibitor efficiency as a function of temperature and concentration of egg shell extract.

A plot of $\log (\theta / 1-\theta)$ vs $\log C$ gave a straight line. This result demonstrated that the inhibition of MS using the egg shell extract was attributed to adsorption of this extract on MS surface. It also confirms the monolayer adsorption. A plot of $\theta$ vs $\log C$ gave a straight line. This indicates the system also obeys Temkin adsorption isotherm. Energy of activation $\left(E_{a}\right)$ value was evaluated from Arrhenius equation. In the presence of egg shell extract the $E_{a}$ values of the inhibitor system was found to be higher than that of the uninhibited system (Table 1). The high $E_{a}$ values indicated an efficient inhibiting action of the inhibitor. Higher activation energy for the corrosion process in the presence of inhibitor leads to a conclusion that probably the inhibitor is found to be adsorbed on the surface by specific adsorption process.

Thermodynamic parameters like $\Delta \mathrm{G}, \Delta \mathrm{H}$ and $\Delta \mathrm{S}$ for adsorption of inhibitor were calculated and presented in Table 1 . The change in free energy values indicate the interaction of inhibitor molecules on mild steel surface and a spontaneous adsorption of the inhibitor on the metal surface. The values of $\Delta \mathrm{H}$ and $\Delta \mathrm{S}$ infer that the adsorption of egg shell extract on MS is enthalpic and entropic controlled. 
Electrochemical measurements were carried out using the electrochemical analyzer Solartron 1280 B. Electrochemical techniques such as linear polarization, Tafel intercept method and electrochemical impedance spectroscopy were carried out. The values of Tafel constants $b_{a}$ and $b_{c}$, corrosion current density $\left(i_{\text {corr }}\right)$ and corrosion potential $\left(\mathrm{E}_{\text {corr }}\right)$ and IE are given in Table 2. It is inferred that $i_{\text {corr }}$ decreases with increase in concentration of egg shell extract in acid medium. This result confirms the inhibitive action of egg shell extract in $0.5 \mathrm{M} \mathrm{H}_{2} \mathrm{SO}_{4}$. Inhibition efficiency calculated using $\mathrm{i}_{\text {corr }}$ was found to be maximum at $0.5 \%$ concentration. The values of Tafel constants $b_{a}$ and $b_{c}$ with respect to the blank, indicate that the inhibitor under study behave like a mixed type inhibitor.

Table 1: Values of $\Delta G, \Delta H$ and $\Delta S$ for various concentrations of egg shell extract for mild steel in $0.5 \mathrm{M} \mathrm{H}_{2} \mathrm{SO}_{4}$.

\begin{tabular}{|c|c|c|c|c|c|c|c|c|c|}
\hline \multirow[t]{2}{*}{$\begin{array}{c}\text { CONC. } \\
(\%)\end{array}$} & \multirow[t]{2}{*}{$\begin{array}{c}\text { Activation } \\
\text { Energy (Ea) } \\
\text { KJJ/mol }\end{array}$} & \multicolumn{6}{|c|}{$\begin{array}{c}\text { Free Energy of Adsorption } \\
(-) \Delta \mathbf{G} \\
\mathbf{K J} / \mathbf{m o l}\end{array}$} & \multirow[t]{2}{*}{$\begin{array}{c}\text { Heat of } \\
\text { Adsorption } \\
(-\Delta \mathbf{H}) \\
\mathbf{K J} / \mathbf{m o l} \\
\end{array}$} & \multirow[t]{2}{*}{$\begin{array}{c}\text { Entropy } \\
\text { Change } \\
(\Delta \mathbf{S}) \\
\mathrm{J} / \mathrm{mol} \\
\end{array}$} \\
\hline & & 303 & 313 & 323 & 333 & 343 & 353 & & \\
\hline Blank & 35.40881 & & - & - & - & - & - & - & - \\
\hline 0.05 & 47.19579 & 18.28 & 20.28 & 19.39 & 20.05 & 19.26 & 19.53 & 15.85 & 11 \\
\hline 0.10 & 61.30723 & 17.29 & 20.03 & 19.13 & 18.56 & 17.62 & 17.87 & 23.00 & 14 \\
\hline 0.15 & 59.7678 & 16.30 & 19.24 & 19.35 & 18.31 & 16.73 & 16.97 & 22.70 & 14.91 \\
\hline 0.20 & 59.02872 & 16.49 & 18.50 & 18.75 & 17.99 & 16.18 & 16.20 & 25.94 & 26.2 \\
\hline 0.25 & 59.6376 & 16.50 & 17.91 & 19.01 & 18.23 & 15.50 & 15.63 & 28.71 & 35.31 \\
\hline 0.30 & 59.98417 & 16.10 & 17.45 & 18.20 & 17.77 & 15.00 & 15.41 & 27.17 & 32.09 \\
\hline 0.35 & 61.72847 & 15.72 & 17.22 & 18.08 & 17.84 & 14.63 & 14.88 & 27.83 & 34.89 \\
\hline 0.40 & 61.86442 & 15.83 & 17.02 & 17.99 & 17.47 & 14.54 & 14.79 & 28.60 & 37.6 \\
\hline 0.45 & 63.71403 & 15.76 & 17.03 & 18.02 & 17.50 & 14.58 & 14.51 & 29.46 & 40.34 \\
\hline 0.50 & 67.62388 & 15.87 & 17.27 & 17.89 & 17.56 & 14.54 & 14.26 & 31.76 & 47.34 \\
\hline
\end{tabular}

Table 2: Electrochemical parameters of $M S$ in the presence of egg shell extract in $0.5 \mathrm{M}$ $\mathrm{H}_{2} \mathrm{SO}_{4}$.

\begin{tabular}{|c|c|c|c|c|c|c|}
\hline S. No. & $\begin{array}{c}\text { Concentration of } \\
\text { Inhibitor }\end{array}$ & $\begin{array}{c}\mathbf{i}_{\text {corr }} \mathbf{x} \mathbf{1 0}^{-\mathbf{3}} \\
\left(\mathbf{m A} / \mathbf{c m}^{\mathbf{2}}\right)\end{array}$ & $\begin{array}{c}\mathbf{b}_{\mathbf{a}} \\
(\mathbf{m V / d e c})\end{array}$ & $\begin{array}{c}\mathbf{b}_{\mathbf{c}} \\
(\mathbf{m V} / \mathbf{d e c})\end{array}$ & $\begin{array}{c}\mathbf{E}_{\text {corr }} \\
(\mathbf{m V} / \mathbf{s e c})\end{array}$ & $\begin{array}{c}\text { IE } \\
(\mathbf{\%})\end{array}$ \\
\hline 1 & Blank & 6.488 & 182 & 166 & -517 & - \\
\hline 2 & $0.1 \%$ & 3.072 & 153 & 133 & -492 & 52.65 \\
\hline 3 & $0.2 \%$ & 1.980 & 186 & 143 & -570 & 69.48 \\
\hline 4 & $0.3 \%$ & 1.785 & 176 & 123 & -503 & 72.48 \\
\hline 5 & $0.4 \%$ & 1.459 & 180 & 130 & -513 & 77.51 \\
\hline 6 & $0.5 \%$ & 1.244 & 157 & 109 & -519 & 80.82 \\
\hline
\end{tabular}

Linear polarization resistance (LPR) in the presence and absence of egg shell extract are presented in the Table 3 and Fig. 3 (a). It is clear that the value of $R_{p}$ increases with increase in concentration of the egg shell extract. Results of Tafel polarization and LPR infer the effectiveness of egg shell extract on MS surface. With increase in concentration of egg shell extract the charge transfer resistance value $\left(\mathrm{R}_{\mathrm{ct}}\right)$ increased. The maximum IE was 
found to be $69.15 \%$ at $0.2 \%$ concentration in the presence of egg shell extract. The decrease in double layer capacitance $\left(\mathrm{C}_{\mathrm{dl}}\right)$ with increase in concentration of egg shell extract indicates the adsorption of the compound on the metal surface. Table 3 infers that the surface coverage $(\theta)$ was found to be 0.6413 at $0.2 \%$ concentration for egg shell extract. The IE obtained using $\mathrm{i}_{\text {corr }}, \mathrm{R}_{\mathrm{p}}, \mathrm{R}_{\mathrm{ct}}$ and $\mathrm{C}_{\mathrm{dl}}$ are represented in the Table 3 and graphically represented in Fig. 3(b).

Table 3: Tabulation of $R_{c t}, R_{p}, C_{d l}$ and their respective IE in presence of egg shell extract.

\begin{tabular}{|c|c|c|c|c|c|c|c|}
\hline S. No. & $\begin{array}{c}\text { Conc. } \\
(\boldsymbol{\%})\end{array}$ & $\begin{array}{c}\mathbf{R}_{\text {ct }} \\
\left(\mathbf{\Omega} \mathbf{c m}^{\mathbf{2}}\right)\end{array}$ & $\begin{array}{c}\mathbf{I E} \\
(\mathbf{\%})\end{array}$ & $\begin{array}{c}\mathbf{R}_{\mathbf{p}} \\
\left(\mathbf{\Omega} \mathbf{~ c m}^{\mathbf{2}}\right)\end{array}$ & $\begin{array}{c}\mathbf{I E} \\
(\boldsymbol{\%})\end{array}$ & $\begin{array}{c}\mathbf{C}_{\mathrm{dl}} \\
\left(\boldsymbol{\mu} \mathbf{\mathbf { c m } ^ { - 2 }}\right)\end{array}$ & $\boldsymbol{\theta}$ \\
\hline 1 & Blank & 15.1 & - & 4.2 & - & 1.96 & - \\
\hline 2 & $0.1 \%$ & 35.81 & 57.83 & 4.3 & 0.93 & 0.966 & 0.5071 \\
\hline 3 & $0.2 \%$ & 48.9 & 69.15 & 5.3 & 19.62 & 0.703 & 0.6413 \\
\hline
\end{tabular}

Impedance diagrams have a semicircular appearance and it indicated that the corrosion of mild steel is controlled by charge transfer process. From the electrochemical measurement, it was clear that egg shell extract is acting profoundly as an excellent inhibitor to reduce acid corrosion on MS surface.
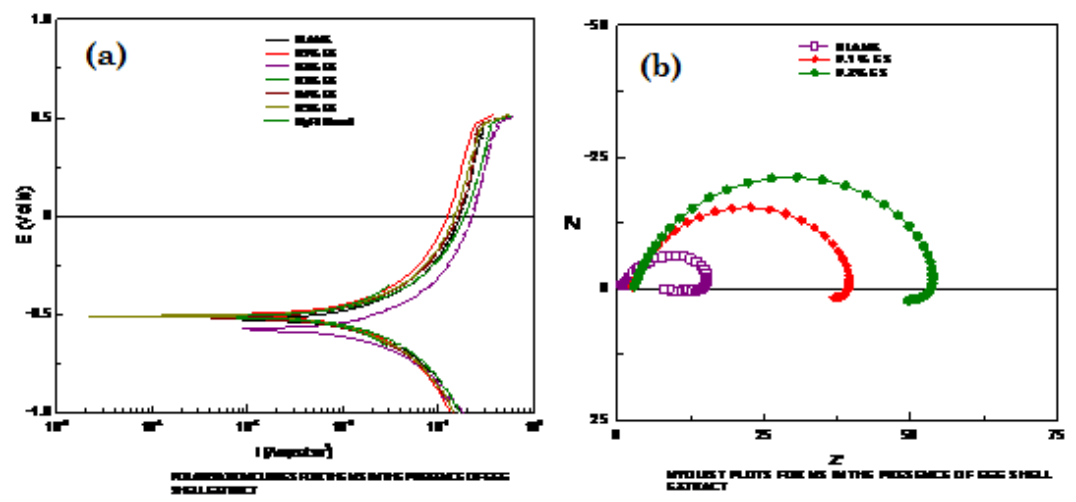

Figure 3: Potentiodynamic polarization (a) and nyquist plot for corrosion of mild steel in presence of inhibitor egg shell extract.

\section{Conclusions}

Bakery waste-egg shell extract has shown a remarkable performance as an inhibitor for mild steel in $\mathrm{H}_{2} \mathrm{SO}_{4}$ solution. The inhibitor used in the present study followed Langmuir adsorption isotherm which indicated the monolayer formation. Thermodynamic parameters confirm the strong interaction between the egg shell extract and mild steel surface. Polarization curves obtained in the presence of the extract indicate that it controls both anodic and cathodic reactions and behave as a mixed type inhibitor. Electrochemical impedance spectroscopy studies also revealed that the corrosion of the $\mathrm{MS}$ in $\mathrm{H}_{2} \mathrm{SO}_{4}$ is controlled by charge transfer process. 


\section{References}

1. H. Ashassi-Sorkhabi, M. R .Majidi and K. Seyvedi, Appl. Surf. Sci., 2002, 225, 176.

2. S. J .Keny, A. G Kumbhar, C. Thinaharan and G. Venkateswaran, Corros. Sci., 2007, 50, 411.

3. C. A. Loto and A. I. Mohammed, Corrosion Prevention and control, 2000, 133(3), 50-56. L. L. Shreir, “Corrosion”, Newnes-butterwoths, London, 1977, $2,9$.

4. A.Y El-Etre., M. Abdallah and Z. E Tantawy. Corros. Sci., 2004, 47, 385.

5. Fabrizio Zucchi, Ibrahim Hashi Omar, Surface Technol., 2002, 24, 391.

6. A. M. Abdel-Gaber, B. A. Abd-El-Nabey, I. M.Sidahmed, A. M El-Zayady and M. Saadawy, Corros. Sci., 2005, 48, 2765.

7. M. Sheyreese Vincent, B. Cyril Okhio, J. Corros. Sci. Eng., 2005, 7, 354.

8. C. G. Gardner, Inhibitors in Acid System, "Corrosion inhibitors", NACE, Houston, Texas, 1973, 156-172.

9. C. G. Eldredge and J. C. Warner, Inhibitors and Passivators, "The Corrosion Hand Book", John Wiley and Sons, New York, 1948, pp. 907-916.

10. I. L. Rezenfeld , "Corrosion inhibitors", Mc Grew-Hill Inc, New York ,1981, pp. 97138.

11. A. A. El Hosary, R. M. Scaleh and A. M. Shams El Din, Corros. Sci., 1972, 12, 897.

12. R. M. Saleh and A. A El. Hosary , $13^{\text {th }}$ Sem. Electrochem., Karaikudi, India , 1972.

13. A. A. El Hosary, M. M. Gauish and R. M. Saleh, Proc. $2^{\text {nd }}$. Int. Symp. Industrial Oriented Basic Electrochemistry, Madras, India, 1980, 6, 18.

14. R. M. Saleh, A. A. Ismail and A. A. El Hosary, Br. Corros. J., 1982, 17, 131.

15. K. Srivastava and P. Srivastava, Br. Corros. J. , 1981, 16, 221.

16. Yu. V. Fadorev and N. A. Kramareva, Metallurgia, 1967, 88.

17. R. M. Hudson, Q. L. Loony and G. J. Warning, Br. Corros. J., 1967, $2,81$.

18. D. Maheswari, R. Rajalakshmi, S. Subhashini, M. Viswanathan and S. Sivakamasundari, Proceedings of Enviro, Coimbatore, India, 2001, 534.

19. S. Subhashini, S. Sathyanarayana, C. Marikkannu and S. Sivakamasundari, 2002, ISAEST VII, 146.

20. R. Rajalakshmi, S. Sathyanarayana, C. Marikkannu and S. Sivakamasundari, 2002, ISAEST VII, 142.

21. G. Manohari and R. Rajalakshmi, $9^{\text {th }}$ Seminar Proceedings, Tamil Nadu State Council for Science and Technology, India, pp. 318 (2001).

22. A. Prithiba, S. Sathiyanarayana, R. Rajalakshmi, S. Sivakamasundari, Proceedings of $11^{\text {th }}$ NCCI, Baroda, India, 2003, 3.

23. R. Rajalakshmi, S. Subhashini, S. Leelavathi, R. Mary Femina, Oriental Journal of Chemistry, 2008, 24,(3), 1085.

24. H. W. Ockerman and C. L. Hansen, Technomic Publishing \& Co, 2000, 54 (4), 121.

25. M. Abdallah and M. Vita, J. Electrochem. Soc. India, 1998, 46(4), 185.

26. A. Abdel and A. El Saied, Transactions of the SAEST, 1981, 16(4), 197. 